\title{
PREDICTION AND PREVENTION METHODS FOR PROTECTION OF SESACHALAM FOREST LOCATED IN CHITTOOR AND KADAPA DISTRICTS, AP, INDIA
}

\author{
Gajjala Ashok $^{1}$, Ch. Ravi Babu ${ }^{2}$, Tiyyagura Anjali ${ }^{3}$, Kota Harika ${ }^{4}$ \\ ${ }^{1}$ Assistant Professor, Electronics \& Communications Engineering, SMGG, AP, India \\ ashok.gajjala826@gmail.com \\ ${ }^{2}$ Associate Professor, Electronics \& Communications Engineering, SMGG, AP, India \\ ravibabuchokka@stmarysgroup.com \\ ${ }^{3}$ Student, Electronics \& Communications Engineering, SMGG, AP, India \\ anjalitiyyagura@gmail.com \\ ${ }^{4}$ Student, Electronics \& Communications Engineering, SMGG, AP, India \\ harikakota8@gmail.com
}

\begin{abstract}
The abstract starts with philosophical point that is "necessity is the mother of invention". The authors have the belief on those words. The view of authors, the research means that clear understanding working mechanism of nature and use of those phenomena for best simpler life of human beings. According to physicist Richard P Feynman said to the students that, "I am not teaching you pupil to get pass in end exams or get job in defence research or any industry, I am trying to make you pupil to understand the nature., which helps us to create miracle things who ever been seenbefore". These philosophy is enough to continue authors research. The paper is mainly inspired by natural problems which is identified at sasachalam forest which is located and spreads over two districts namelychittoor and Kadapa, Andra Pradesh. The main problem we found that is; the forest has highdensity of sandal wood trees. The world knows that, the sandal wood is very precious in everyday life of human beings, like medicine, house equipment's and it finds so many interesting potential applications in many fields. This makes, these trees have greater role and have very richness in market. This makes in society the thought of smuggling that the persons cutthe trees illegally and export to another country to earn money. The forest department is unable to catch them in all situations.The government of AP believes that most of the income to government from them (sandal wood trees). And one more problem was identified by authors that read from newspapers, smugglers were killed the police officers in stopping of cutting sandal trees. These are two outstanding problems what the authors have in mind. Here the authors build the interesting system to prevent the cutting of trees and also warns the remoting station as well. Sometimes natural disasters may also collapse the trees like forest fires and high density rain. This information is also knowing to officers because they have to collect trees to market.Here the problem is modeled into three categories 1) Someone may cut the trees. 2) Due to rain the trees may fall down 3) Forest fires. In first problem someone may cuts trees, in that situation, the proposed method of fining the position detection continuously and sends message to remote station if tree is safe it sends message "Normal Positions". If anybody cuts the tree, the systems wait until reaching maximum slope value and beyond that it sends message immediately to remote arealike" Tree is fallen" and officers takes an action depending, which tree is cut. And second case is disaster, if trees fall down we need to collect those trees for marketing, this work is helpful in this situations also. And final one, the authors suggest that fire detection using sensors and to prevent fire we use more traditional natural method to stop. This paper is very helpful to trace out smugglers, enhancing monitoring capability, reduction in man power for protection and finally saves government income. The main plane is to detect tree position based on slop of tree and sends feedback to remote site for to take necessary actions. The main motive is serve technology to real time world problems to solve and makes the world much simpler in all aspects.
\end{abstract}

Keywords: Arduino, Accelerometer, Sensors, Embedded Systems

\section{INTRODUCTION}

The world is changed a lot in recent days because technology influences all the fields of science and technology that medicine, electronic industries, chemistry, anatomical studies etc. In the paper tried to develop an interesting application systems to protect the sandal wood tries. The development systems include the most sophisticated process to detect the smuggler. Here embedded systems, sensor technology, hardware software co-design, embedded c programming is need to build.

\section{PROBLEM DEFINING}

The paper is mainly inspired by natural problems which is identified at sasachalam forest spreads over two districts namely chittoor and Kadapa. The main problem here is; the forest is densely composed of sandal wood trees. The world 
knows that, the sandal wood is very precious in many fields like medicine, house equipment's and it finds so many interesting stuff applications. This makes, these trees have greater role and very rich in market. The persons cut trees illegally and export to another country to earn money. The forest department is unable to catch them in all situations. The government of AP believes that most of the income from them (sandal wood trees). Here the authors build the interesting system to catch them and also warns the remoting station as well. Sometimes natural disasters may also collapse the trees like forest fires and high density rain.

Here the problem is arising mainly three types

1) Someone may cut.

2) Due to rain trees may fall down

3) Forest fires.

In first problem someone may cuts trees, in that situation, the proposed method of fining the position detection continuously and sends message to remote station if tree is safe it sends message "Normal Positions". If anybody cuts the tree, the systems wait until reaching maximum slop value and beyond that it sends message immediately to remote area like" Tree is fallen" and officers takes an action depending, which tree is cut. And second case is disaster, if trees fall down we need to collect those trees for marketing, this work is helpful in this situations. And final one, the authors suggest more traditional natural method to stop forest fires. This paper is very helpful to trace out smugglers, enhancing monitoring capability, reduction in man power for protection and finally saves government income. The main plan is to detect tree position based on slop of tree and sends feedback to remote site for to take necessary actions. The main motive is serve technology to real time world problems to solve and makes the world much simpler in all aspects.

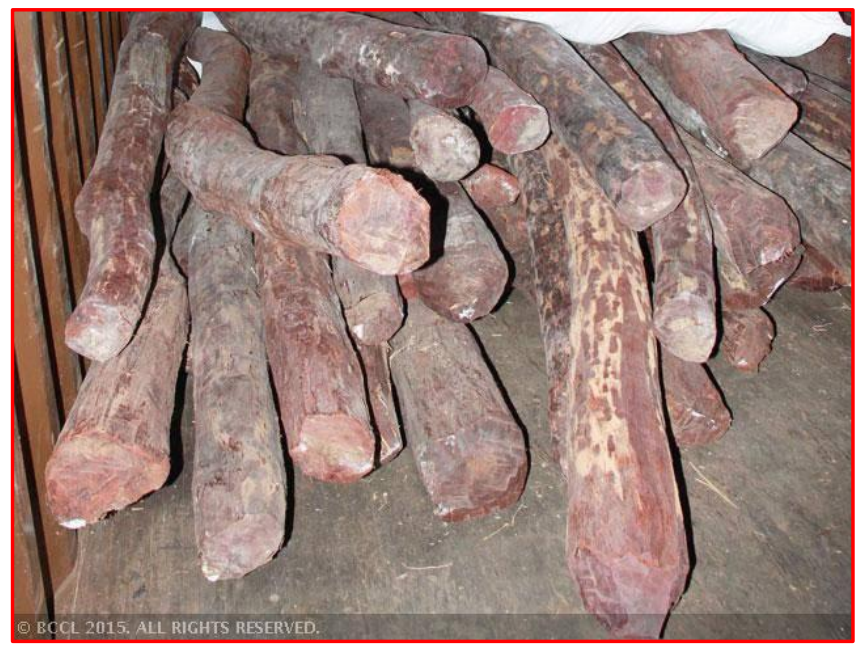

Figure 1: Trunk of sandalwood

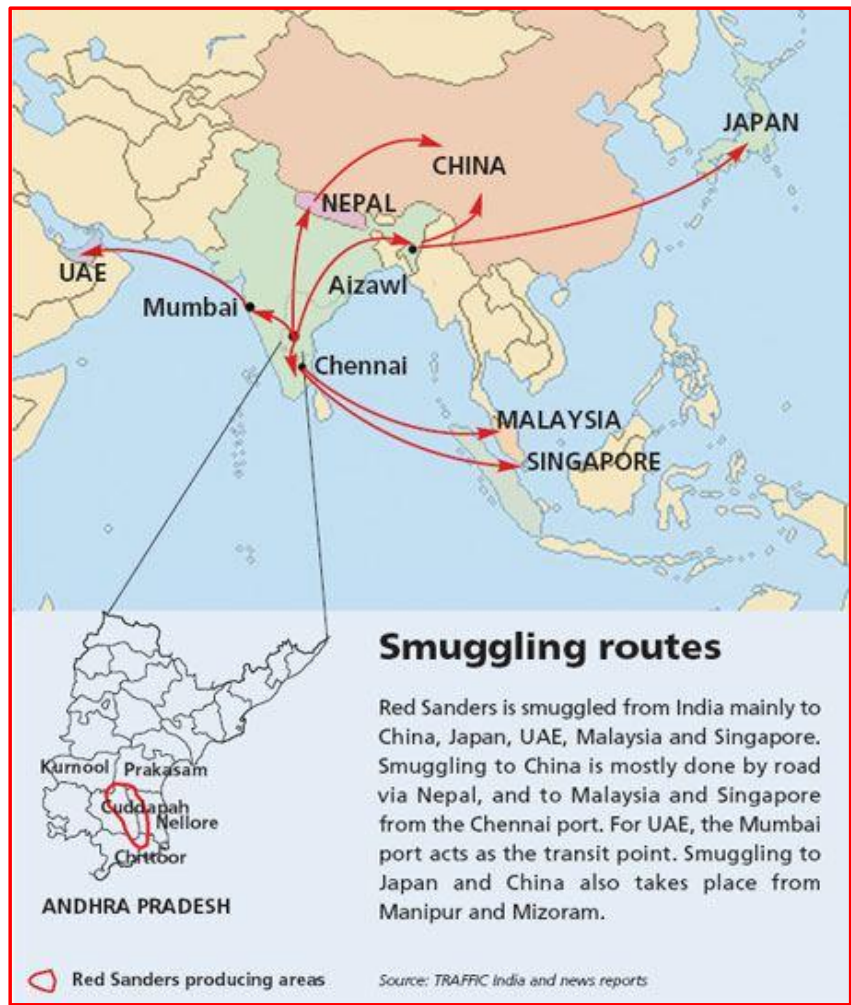

Figure 2: Smuggler Arial root map

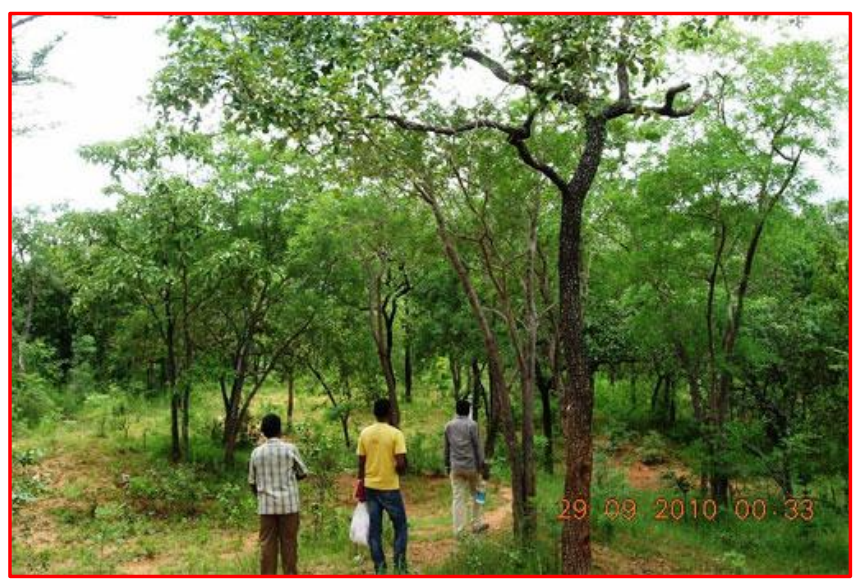

Figure 3: Sandalwood trees

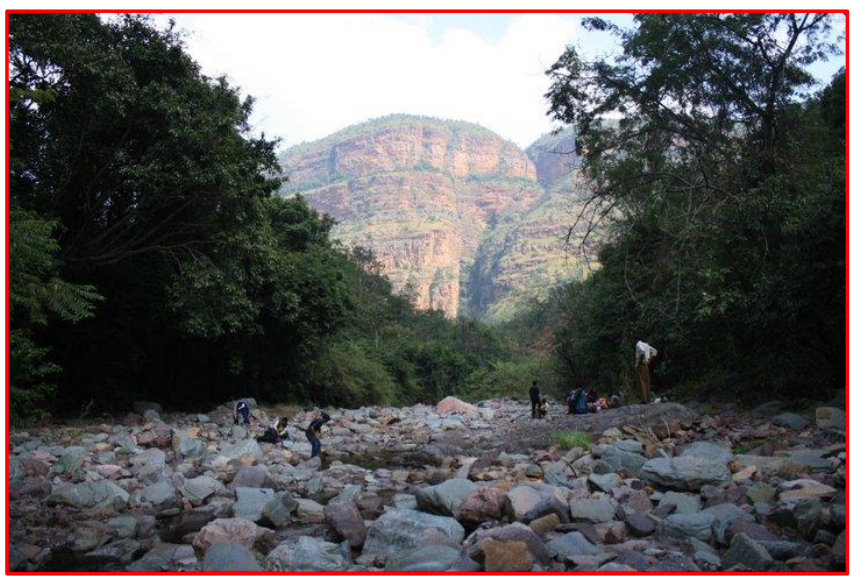

Figure 4: Snapshot of Sesachalam Forest 


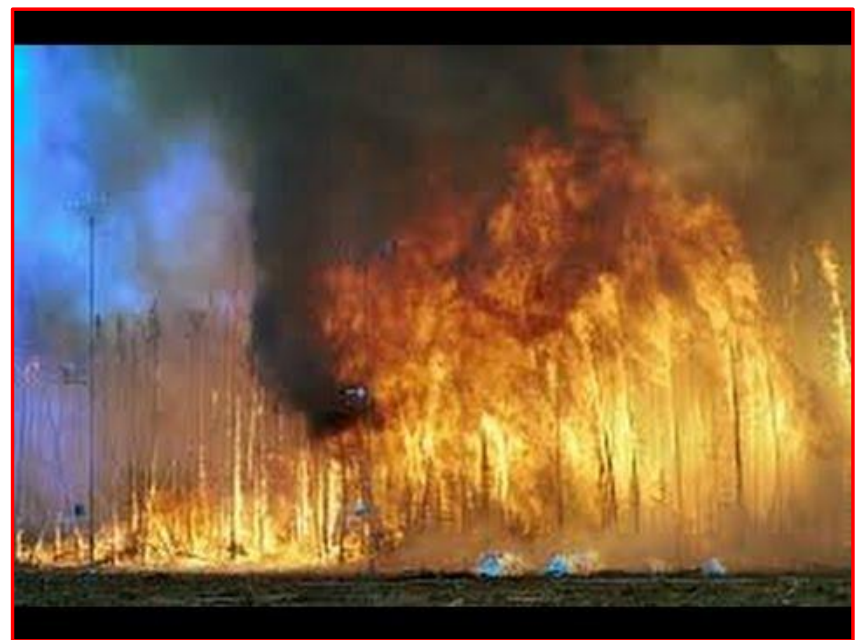

Figure 5: Forest firing Problems

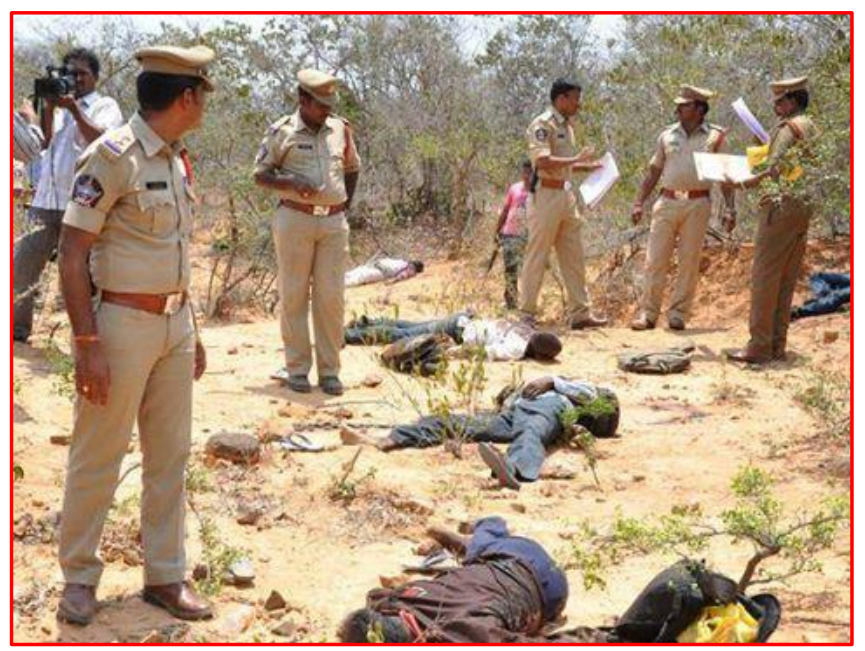

Figure 6: Smugglers problems

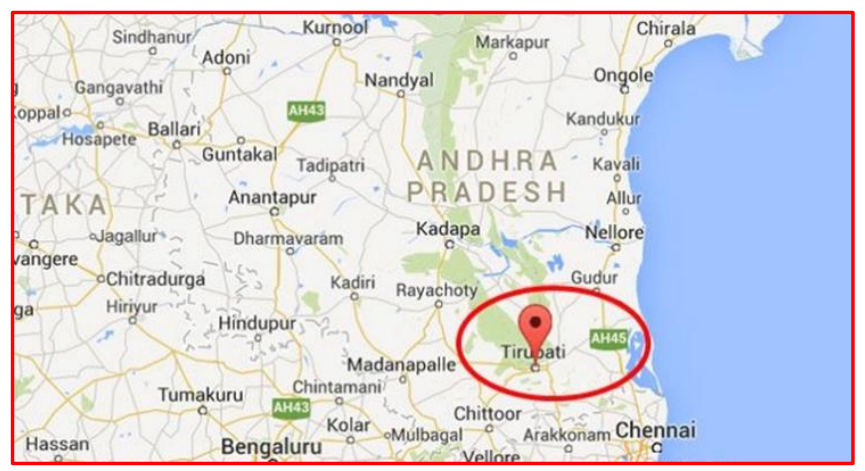

Figure 7: Satellite view of Sesachal Forest in A.P

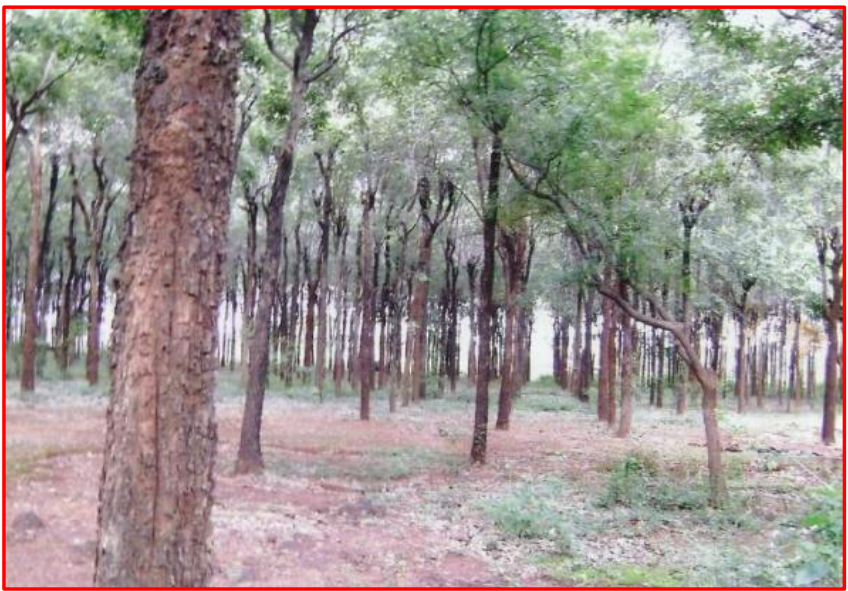

Figure 8: Density of the sandal wood trees in Sasachalam forest

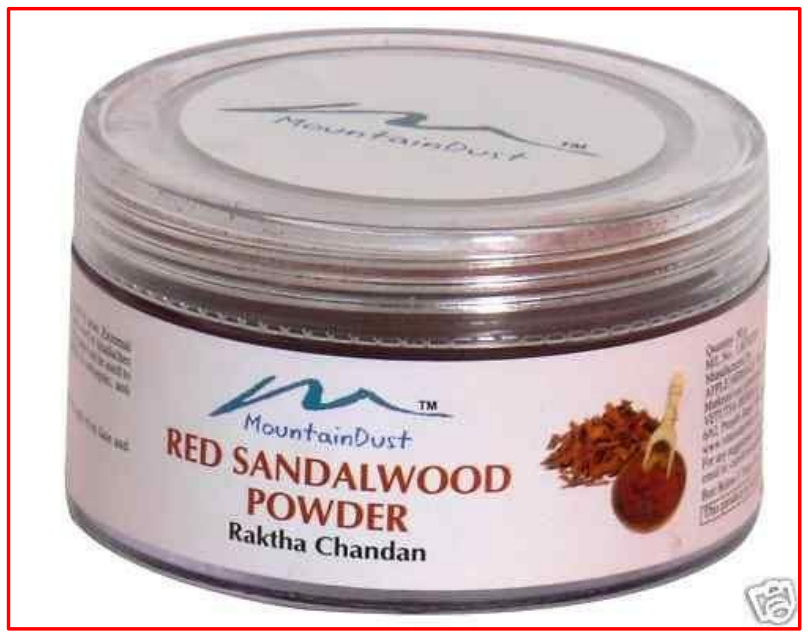

Figure 9: Sandalwood for Cosmetics

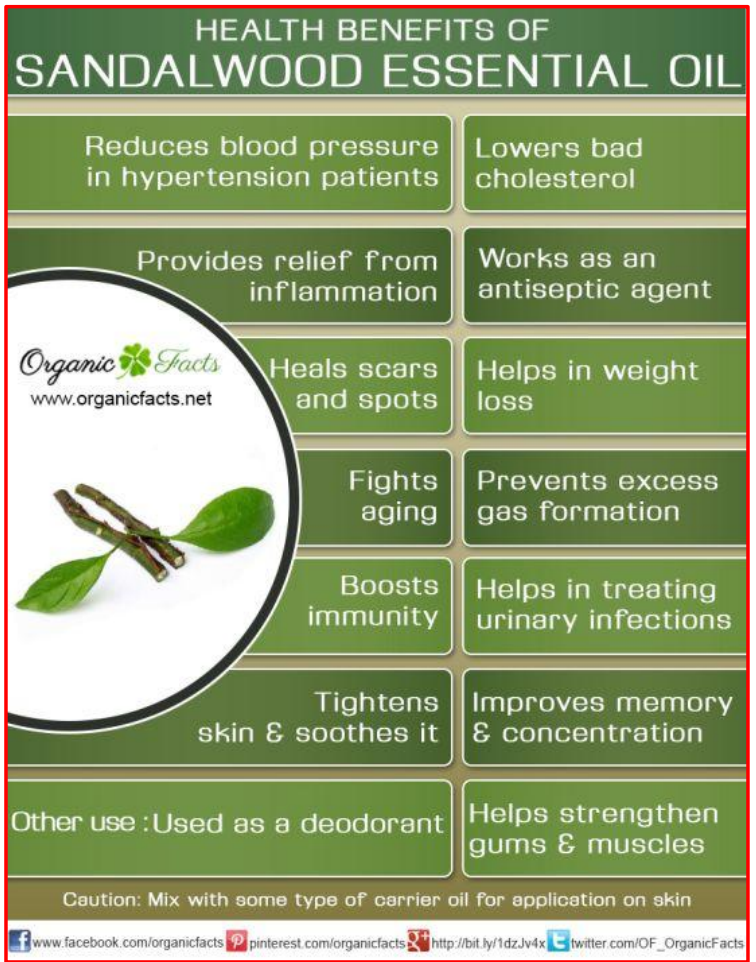

Figure 10: Applications of sandalwood in medical industry 


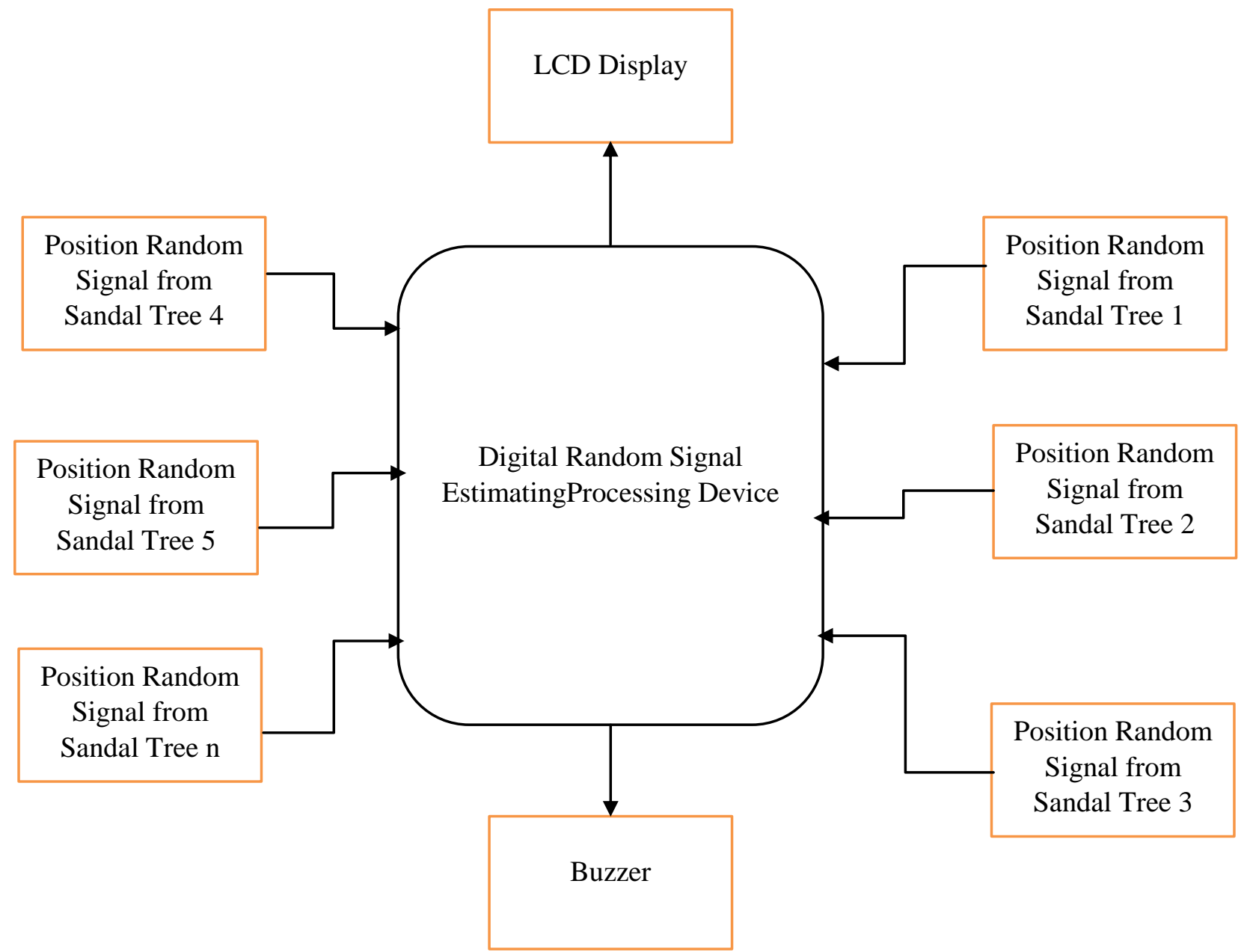

Figure 11: Architecture of the developed Position Estimating system

The mathematical modelling of the signal from the N Sandal trees are as

Signal 1: $Y(t)=\int_{-\infty}^{+\infty} x(t) * h(t-T) d t$

Signal 2: $Y(t)=\int_{-\infty}^{+\infty} x(t) * h(t-T) d t$

Signal 3: $Y(t)=\int_{-\infty}^{+\infty} x(t) * h(t-T) d t$

Signal n: $Y(t)=\int_{-\infty}^{+\infty} x(t) * h(t-T) d t$

The above equation represents the physical wave nature of the position of the tree and its nature in nature random signal. We need sophisticated system, who can process these signal

in more desirable way to worn the monitoring station person to know the status of the particular tree.

If anyone cut the tree the sophisticated system understands the signal and sends feedback to the monitoring station. They will alert by the systems an acts accordingly to trace the smugglers. We need random signal processing digital computing device and it took the decision. In mathematical modelling signal1, signal 2, signal3 ...... signal $\mathrm{N}$ shows the signals from the sandal trees. The method is efficient to trace down the smugglers.

\section{RESULTS \& DISCUSSIONS}

The above mentioned things are clear that the value of Sandal wood in the society, there is a need to protect sandal wood from smugglers and natural disasters as well. We implemented the protection with high quality random function estimator and controller. The system is more flexible for catching up the smugglers. The results of the practical detection systems as shows below at various stages. The figures on following shows the estimation of the tree position at various level and action accordingly.

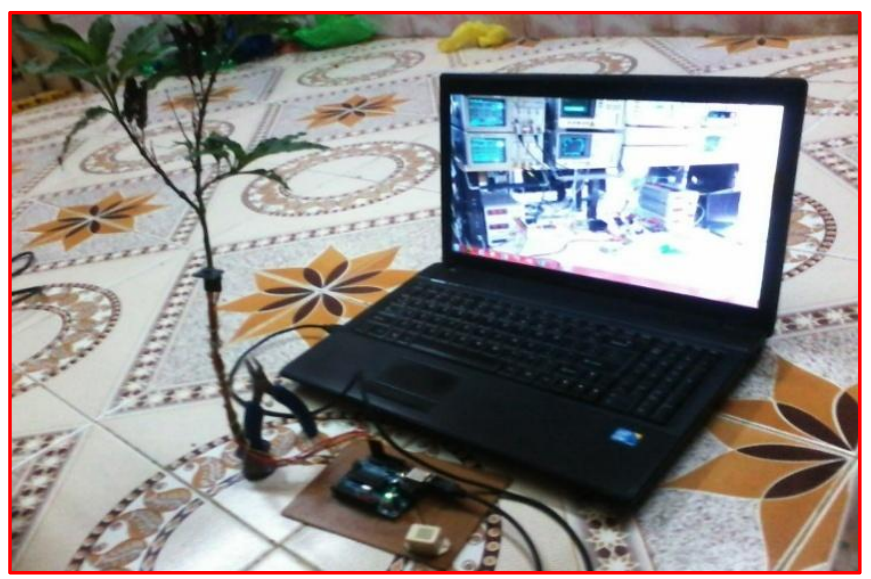

Figure13: Sensor Interfaced to Sandal tree 


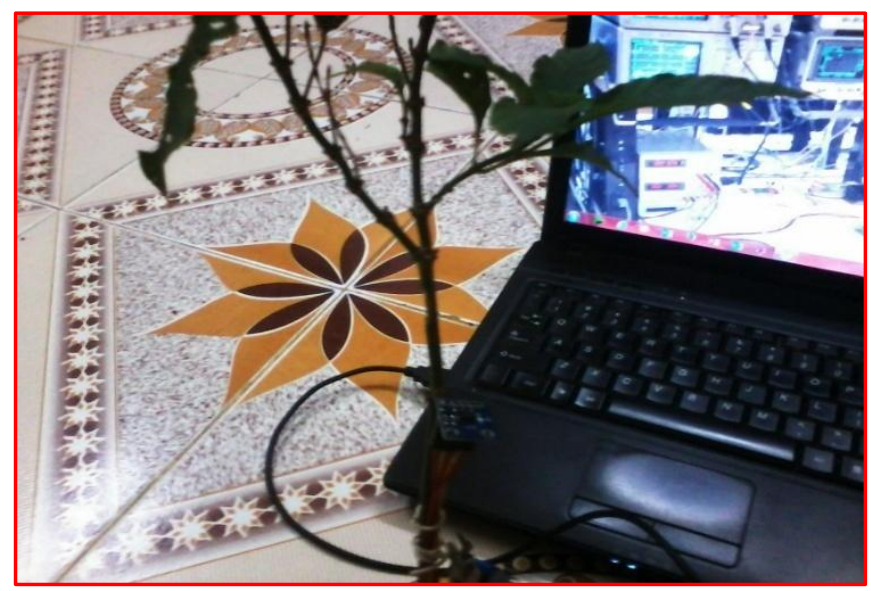

Figure 14: Accelerometer meter view

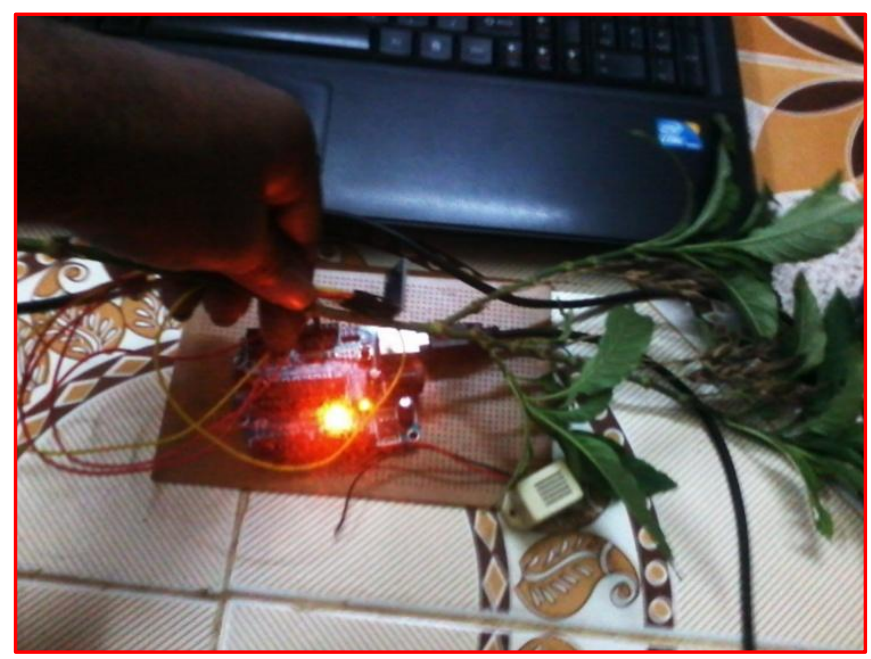

Figure 15: Tree fallen position

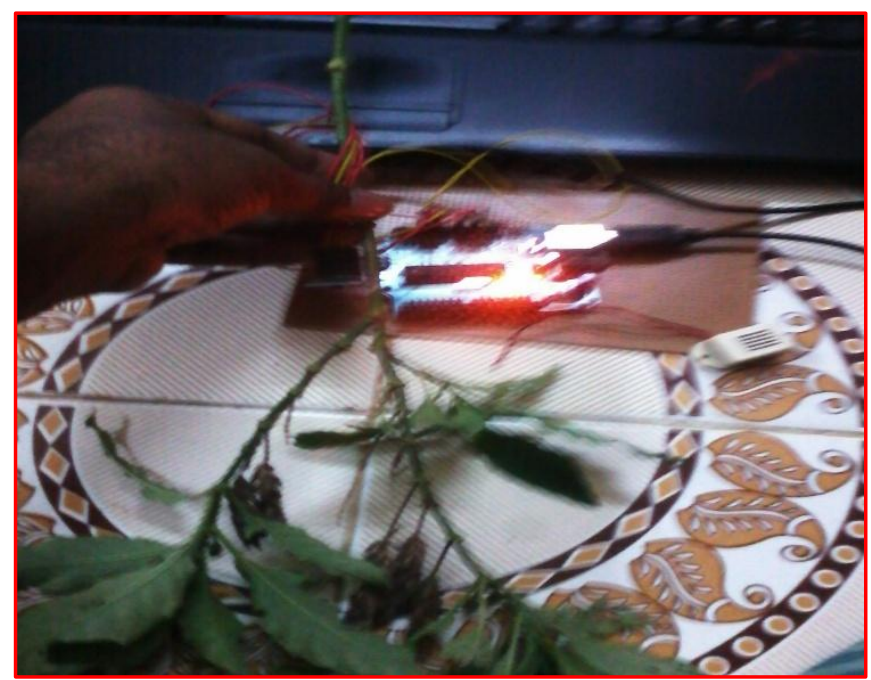

Figure 16: Tree fallen position

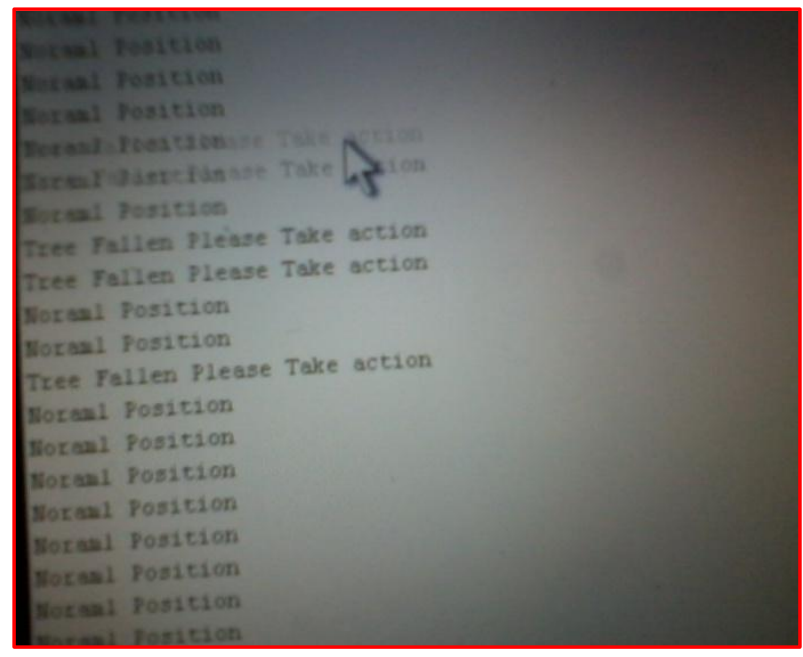

Figure 17: Results display1

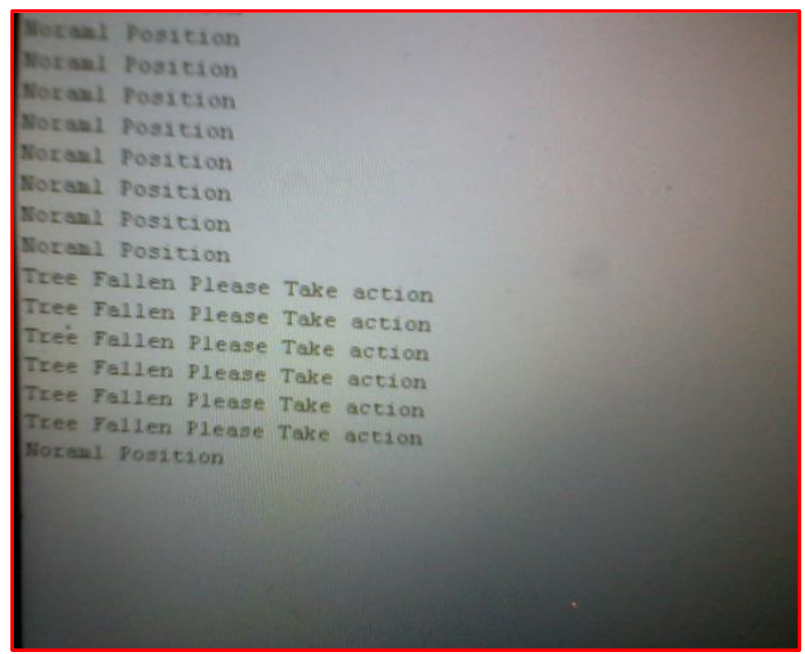

Figure 18: Results display2

\section{CONCLUSION}

In infer, this project is more suitable for Govt of AP. Let ou know how it? main economy generating for Andhra Pradesh is from sandal wood. The smuggler is hardly trying to smuggled these sandal wood. We read from newspapers that smuggler killed police officers in smuggling. The project what we developed is perfectly monitoring the each and every tree position. The information about particular sandal tree continuously feeding to monitoring station. If anybody cuts the trees, the system what we developed alerts the police officer and also it has another feature that gives where the tree is located. Based on the data given by the system police officers takes an action accordingly. So the project saves lot of money in cores of amount to the Govt.

\section{ACKNOWLEDGEMENTS}

Authors would like to thankful to Rev. Dr KVK Rao, Chairman of St.Mary's Group to his great encouragement towards Research .And Author one would like thankful to his Physics Guru R. SrinivasaMurty to his encouragement at all the time and also would llike to mention the students by names Anjali \&Harika, they have good handworkers and have a enthusiastic nature, such students needed to society. 
Anjali: First of all I fell happy for giving this wonderful opportunity for publishing this paper. I feel thankful to our Department helping me regarding to this paper. And also thank our vice Principal Ch. Ravi Babu andIn charge Director Y. Raghavagaru, those who facilitate awesome R \& $\mathrm{D}$ in our college.

Harika: I would like to thankful to almighty, parents and My Gurus at SMGG to their encouragement and honest help. The way the teacher of SMGG teaches is incredible to learn and develops intuitive thinking as well.

\section{REFERENCES}

[1] Einstein, Albert (1920). "20". Relativity: The Special and General Theory. New York: Henry Holt. p. 168. ISBN 1-58734-092-5.

[2] Penrose, Roger (2005) [2004]. "17.4 The Principle of Equivalence". The Road to Reality. New York: Knopf. pp. 393-394. ISBN 0-470-08578-9.

[3]Doscher, James. "Accelerometer Design and Applications". Analog Devices. Archived (PDF) from the original on 13 December 2008. Retrieved 2008-12-23.

[4] Shepard, Emily L. C.; Wilson, Rory P.; Quintana, Flavio; Laich, Agustina Gómez; Liebsch, Nikolai; Albaredas, Diego A.; Halsey, Lewis G.; Gleiss, Adrian; Morgan, David T.; Myers, Andrew E.; Newman, Chris; Macdonald, David W. "Identification of animal movement patterns using tri-axial accelerometry" (PDF). int-res.com. Archived (PDF) from the original on 8 November 2012. Retrieved 2014-09-11.

[5] Kawabe et al. (2003) Fisheries Science 69 (5):959 - 965

[6] Wilson et al. (2006) Journal of Animal Ecology:75 (5): $1081-1090$

[7] Klubnik, Renard; Sullivan, Ron. "Know the Age of your Pumps" (PDF). Archived (PDF) from the original on 11 September 2014.

[8] Wilcoxon Research. "Guidance for mounting 4-20 mA vibration sensors on fans" (PDF). Archived from the original on 11 September 2014. Retrieved 11 September 2014.

[9] Tilting trains shorten transit time. Memagazine.org. Retrieved on 17 October 2011.

[10] Michael Randall. "USGS - volcano monitoring". Retrieved 12 September 2014.

[11]"These Apps Are Made For Walking - NYTimes.com". Retrieved 12 September 2014.

[12] "Mullard: DDR100 Accelerometer Double Diode data sheet" (PDF). Retrieved 7 May 2013.

[13] O. Sircovich Saar "Dynamics in the Practice of Structural Design" 2006 WIT Press ISBN 1-84564-161-2

[14] Nosovitz, Dan. "NFL Testing Helmets With ImpactSensing Accelerometers for Concussion Analysis". Popular Science. Archived from the original on 12 September 2014.

[15] Irvin Hussein López-Nava. "Towards Ubiquitous Acquisition and Processing of Gait Parameters - Springer". Retrieved 12 September 2014.

[16] Lopez-Nava I. H. et Munoz-Melendez A. (2010). Towards ubiquitous acquisition and processing of gait parameters. In 9th Mexican International Conference on Artificial Intelligence, Hidalgo, Mexico.

[17]"'Vertical Speed Measurement", by Ed Hahn in sci.aeronautics.airliners, 1996-11-22". Retrieved 12 September 2014.
[18] US patent 6640165, Hayward, Kirk W. and Stephenson, Larry G., "Method and system of determining altitude of flying object", issued 2003-10-28

\section{BIOGRAPHIES}

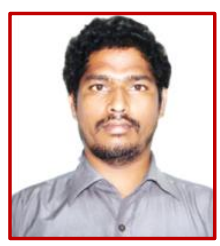

G Ashok, $\mathrm{He}$ is currently working as Assistant Processor, Dept. of ECE, SMGG, Guntur. He teaches at SMGG, signal \&systems, Probability \& Stochastic Processing, Digital Signal Processing, Circuits \&Systems, and Digital Image Processing.He has 3 and half years of Teaching \& Research Experience. He published few International Journal's. He holdB.Tech\&M.Tech from JNTUA. Area of Research, Electromagnetism, Artificial Neural Networks, Superconductivity, Intellectual systems design. Follow him on:

http:Iwww.howtoadapttonewtechonology.blogspot.com

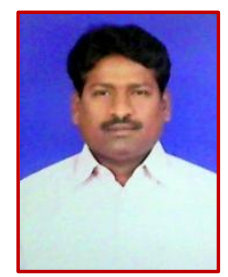

Ch Ravi Babu, He is currently working as Associate Processor, Dept. of ECE, St.Mary's Group of Institutions Hyderabad, Deshmukhi (V),Nalgonda(DT), Telangana, India. He holds B.Tech form S.V. University, Tirupati at N.B.K. R Institute of Science and Technology in the year 1999 \& M. Tech from JNTUH at St. Mary's Group of Institutions Hyderabad.He has 16 and half years of Teaching \& Real Time Industrial Experience and actives member in administrative activities too. He worked as Zonal Incharge \& Construction incharge in the field of fiber optic communication at Sri Sai Ram Construction Hyderabad, from August $3^{\text {rd }}, 1999$ to June $30^{\text {th }} 2002$. After that he hold the designation as Associate professor at St. Mary's Group of Institutions Hyderabad from 2002 to till date. He teaches at SMG, Electronic devices and circuits, signal \&systems, Probability \& Stochastic Processing, Digital Signal Processing, Circuits \&Systems, and Digital Image Processing. Area of Research Are Digital Systems, Electromagnetism, Embedded Systems.

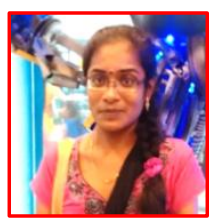

Anjali T, completed B.Tech in stream of ECE in the year 2016 from JNTU Kakinada at St.Mary's Group of Institutions Guntur. She has good academic credentials. She skilled in sports like running, Co-Co. She presented a few paper presentations in National Level Seminars and attended workshops and project expos.Her research interests are VLSI Design and Hardware \& Software Co-Design

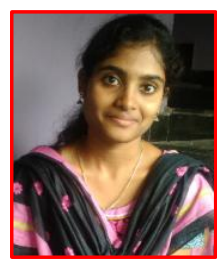

Harika. K, completed B.Tech in stream of ECE in the year 2016 from JNTU Kakinada at St. Mary's Group of Institutions GunturShe has good and fantastic enthusiastic nature of learning new technologies. She spends a lot time to learn new things, and thinks in logical manner. She asks a lot questions during lecture. She presented a few paper presentations in National Level Seminars and attended workshops too. This is the fundamental quality of student. Her research interest in Embedded Systems. 